\title{
Using bioabsorbable fixation systems in the treatment of pediatric skull deformities leads to good outcomes and low morbidity
}

\author{
Melanie G. Hayden Gephart • Joslyn I. Woodard • \\ Robert T. Arrigo • H. Peter Lorenz • \\ Stephen A. Schendel • Michael S. B. Edwards • \\ Raphael Guzman
}

Received: 13 June 2012 / Accepted: 20 July 2012 /Published online: 26 October 2012

(C) Springer-Verlag Berlin Heidelberg 2012

\begin{abstract}
Background Bioabsorbable fixation systems have been widely employed in pediatric patients for cranial reconstruction, obviating the complications of hardware migration and imaging artifact occurring with metallic implants. Recent concern over complications unique to
\end{abstract}

Electronic supplementary material The online version of this article (doi:10.1007/s00381-012-1938-y) contains supplementary material, which is available to authorized users.

M. G. Hayden Gephart

Department of Neurosurgery, Stanford University Medical Center, Stanford, CA 94304, USA

J. I. Woodard $\cdot$ R. T. Arrigo

Stanford University School of Medicine,

Stanford, CA 94305, USA

M. S. B. Edwards $\cdot$ R. Guzman $(\bowtie)$

Division of Pediatric Neurosurgery, Lucile Packard Children's

Hospital,

Stanford, CA 94304, USA

e-mail: raphaelg@stanford.edu

H. P. Lorenz $\cdot$ S. A. Schendel

Division of Pediatric Plastic Surgery, Stanford University Medical Center,

Stanford, CA 94304, USA

\section{J. I. Woodard}

Stanford Neurosurgery Department,

Menlo Park, CA 94304, USA

e-mail: jiw2@stanford.edu

R. Guzman

Division of Pediatric Neurosurgery, University Children's

Hospital of Basel,

Basel 4031, Switzerland

email: guzmanr@uhbs.ch bioabsorbable materials, such as inflammatory reaction and incomplete resorption, necessitates additional conclusive studies to further validate their use in pediatric neurosurgery and craniofacial surgery. Likewise, longterm follow-up in this clinical cohort has not previously been described.

Methods We included consecutive pediatric patients under the age of 2, from Lucile Packard Children's Hospital, who underwent cranial vault reconstruction with the use of a bioabsorbable fixation system between 2003 and 2010. Hospital records were queried for patient characteristics, intraoperative data, and postoperative complications.

Results Ninety-five patients with the following preoperative pathologies were analyzed: craniosynostosis (87), cloverleaf skull (5), frontonasal dysplasia (1), and frontonasal encephalocele (2). Median age was 6 months (range 1-24 months). Average case duration was 204 minutes (range 40-392 min), with median of $154 \mathrm{~mL}$ blood loss (range 30-500 mL). Ninety-three percent of patients had 1-4 plates implanted with $48 \%$ receiving three plates. The median number of screws used was 59 (range 0-130). The median length of hospital stay was 4 days (range 2-127 days) with an average follow-up of 22 months (five postoperative visits). The complications related to hardware implantation included swelling $(1 \%)$ and broken hardware $(1 \%)$, the latter of which required reoperation.

Discussion The bioabsorbable fixation systems for cranial vault reconstruction in children less than 2 years of age is safe with tolerable morbidity rates.

Keywords Bioabsorbable $\cdot$ Craniosynostosis $\cdot$ Pediatric neurosurgery $\cdot$ Pediatric skull deformities $\cdot$ Resorbable plates 


\section{Introduction}

Bioabsorbable fixation systems have been widely employed for use in pediatric patients for cranial reconstruction since 1997, obviating the complications of hardware migration and imaging artifact occurring with metallic implants. Recent concern over complications unique to bioabsorbable materials, such as inflammatory reaction and incomplete resorption [3, 8, 10, 14, 15], necessitates additional conclusive studies to further validate their use in pediatric craniofacial surgery. Here, we present a retrospective analysis of children younger than 2 years of age who underwent craniofacial procedures with a bioabsorbable plating system.

\section{Methods}

This was a HIPPA-compliant, IRB-approved research protocol, accessing password and firewall-protected patient databases. Hospital records from Lucile Packard Children's Hospital (LPCH) were retrospectively queried on consecutive pediatric patients who underwent cranial vault reconstruction with a bioabsorbable plating system (RapidSorb ${ }^{\circledR}$ Synthes CMF, West Chester, PA, L-lactide-co-glycolide) between 2003 and 2010. At our institution, this is the predominant system employed; therefore, to remove any potential variability between industrial product formulation, only patients with this specific bioabsorbable fixation system were included. Inclusion criteria included age less than 2 years, diagnosis of a skull or facial deformity requiring combined neurosurgery and plastic surgical intervention, and intraoperative use of bioabsorbable plates. Hospital records were queried for patient demographics, preoperative diagnoses, intraoperative data, and postoperative complications.

Funding was provided in part by an industry sponsored indirect educational grant to Stanford University to fund aspects of this study. The Synthes company administration and representatives had no contact with the study staff regarding the study design or results. Furthermore, the outcome of this study was not discussed with industry prior to data analysis or manuscript production. Ethical considerations of this educational grant were weighed heavily and ultimately approved by the Dean of the Stanford University School of Medicine.

\section{Results}

Ninety-five patients with the following preoperative pathologies were analyzed: craniosynostosis $(n=87)$, cloverleaf skull $(n=5)$, frontonasal dysplasia $(n=1)$, and frontonasal encephalocele $(n=2)$. Median age was 6 months (range $1-24$ months), with $83 \%$ of patients less than 12 months of age. Forty-six percent of patients were female $(n=44)$ and $54 \%$ were male $(n=51)$. Demographic information as documented by selfreport from patients' families was collected and included an ethnic distribution of: White, non-Hispanic (55\%), Hispanic (29\%), Black (2\%), Asian (13\%), and Native American (1\%). Sixty percent of patients had private insurance, $39 \%$ had Medi-Cal, and one patient was without insurance.

Table 1 details the diagnoses included in the study, including the suture involved and the relative frequency of any associated syndrome. Three cases were identified as reoperations. Comorbidities were found in $22 \%$ of patients $(n=21)$ with each detailed by system in Table 2 . Eleven patients had preoperative developmental delay.

Average case duration was $204 \mathrm{~min}$ (range 40-392 $\mathrm{min}$ ), with median of $154 \mathrm{~mL}$ blood loss (range 30-500 mL). Postoperatively, the threshold to receive a transfusion was a hematocrit of 22. Ninety-three percent of patients received a blood transfusion either intra- or postoperatively, with a median transfused volume of $150 \mathrm{~mL}$ (range $0-1,000 \mathrm{~mL}$ ). Ninety-three percent of patients had one to four plates implanted with $48 \%$ receiving three plates (Table 3 ). The median number of screws used was 59 (range 0-130).

Table 1 Diagnosis, syndromes, and involved sutures

\begin{tabular}{|c|c|c|}
\hline & \multicolumn{2}{|c|}{ Patients } \\
\hline & Cases & $(\%)$ \\
\hline \multicolumn{3}{|l|}{ Diagnosis } \\
\hline Craniosynostosis & 87 & $(92)$ \\
\hline Frontonasal dysplasia & 1 & $(1.1)$ \\
\hline Frontonasal encephalocele & 2 & $(2.1)$ \\
\hline Kleeblattschädel & 5 & $(5.3)$ \\
\hline Total & 95 & $(100)$ \\
\hline \multicolumn{3}{|l|}{ Suture involvement ${ }^{\mathrm{a}}$} \\
\hline Unilateral coronal & 28 & (29) \\
\hline Bilateral coronal & 12 & (13) \\
\hline Lamboid & 7 & (7.4) \\
\hline Sagittal & 10 & (11) \\
\hline Multiple & 6 & $(6.3)$ \\
\hline Total & 87 & $(91)$ \\
\hline \multicolumn{3}{|l|}{ Syndrome $^{\mathrm{b}}$} \\
\hline Apert & 3 & $(3.2)$ \\
\hline Crouzon & 2 & $(2.1)$ \\
\hline Downs & 1 & $(1.1)$ \\
\hline Muenke & 1 & $(1.1)$ \\
\hline Pfeiffer & 1 & $(1.1)$ \\
\hline Saethre-Chotzen & 3 & $(3.2)$ \\
\hline Sotos & 1 & $(1.1)$ \\
\hline Total & 12 & (13) \\
\hline
\end{tabular}


Table 2 Medical comorbidities by system in 21 patients

\begin{tabular}{lll}
\hline System and disease & Cases & $(\%)$ \\
\hline Cardiovascular & 4 & $(4.2)$ \\
Endocrine & 1 & $(1.1)$ \\
Gastrointestinal & 3 & $(3.2)$ \\
Genetic & 2 & $(2.1)$ \\
Neurologic & 10 & $(11)$ \\
Prematurity & 2 & $(2.1)$ \\
Pulmonary & 5 & $(5.3)$ \\
Renal & 1 & $(1.1)$ \\
Torticollis & 3 & $(3.2)$ \\
Total & 32 & \\
\hline
\end{tabular}

The median length of hospital stay was 4 days (range 2127 days). The average follow-up was 22 months (range 0.574; median 17) and the patients had an average of five postoperative visits (range 1-10, median 5). Overall, $91 \%$ of all cases had no complications. Postoperative complications related to surgery included pneumonia (1\%) and superficial wound infection ( $3 \%$ ). Complications related to the hardware included one broken strut plate $(1 \%)$ and one patient with swelling at the site of the plate 7 months after surgery with complete resolution at 11 months $(1 \%)$. The wound infections were superficial and required only outpatient antibiotic treatment for resolution. Three patients were preoperatively determined to require a staged reconstruction for their cranial deformity. Two cases of unanticipated reoperations included one for persistent facial and cranial deformity several months after surgery and one for broken hardware on postoperative day 1 .

\section{Discussion}

Surgical correction of cranial and facial deformities in children requires the unique consideration of the child's growing skull while maintaining acceptable stability to enable osteogenesis.

Table 3 Distribution of the number of plates installed per patient

\begin{tabular}{lll}
\hline Number of plates & Patients & \\
\cline { 2 - 3 } & Cases & $(\%)$ \\
\hline 1 & 8 & $(8.4)$ \\
2 & 20 & $(21.1)$ \\
3 & 46 & $(48.4)$ \\
4 & 14 & $(14.7)$ \\
5 & 6 & $(6.3)$ \\
$-^{\mathrm{a}}$ & - & - \\
9 & 1 & $(1.1)$ \\
\hline
\end{tabular}

${ }^{\mathrm{a}}$ No patients required six, seven, or eight plates
Resorbable plates and screws attempt to avoid the problems with metal fixation systems, including erosion into the dura and brain parenchyma, imaging artifact, and restriction of bone growth. Multiple studies have documented the use of these products in the repair of craniosynostosis and other pediatric cranial deformities (Table 4).

Resorbable fixation systems in cranial surgery have been found to provide stable cranial fixation, which allow for normal expansion of the cranial vault, while avoiding problems with migration or increased complication rates compared to metal alternatives [1, 7-9, 12, 14, 15, 17]. Complications with bioavailable fixation systems include inadequate resorption, osteolysis, inflammatory foreign body reaction, plate extrusion, and infection $[3,8,10,14$, 15]. Recently, the use of these materials has expanded to include combination with hydroxyapatite cement for more extensive reconstruction procedures $[4,11,16]$, reconstruction after trauma [6], and reconstruction of the orbit [2]. Animal studies have shown negligible involvement of the dura and brain parenchyma directly underlying the bioabsorbable materials [5]. Histologic examination of resorbable plates has showed fibrous encapsulation of the plates, with a foreign body macrophage and giant cell reaction and calcification [5, 13, 14].

Recent concerns, particularly in regard to the inflammatory reaction, necessitated further evaluation of the risks and benefits of resorbable fixation systems in young children [3]. To decrease variability in age, surgeon, and implants, we elected to study children under the age of 2 , where the same resorbable system was utilized, operated on by our combined pediatric neurosurgery and plastic surgery team at LPCH. As with previous studies, over $90 \%$ of patients had an excellent outcome with only one case of inflammation or broken hardware. Inflammation typically occurs within the first 12 months after implantation [3] which was accounted for with our mean follow-up time of 22 months. Another factor that can influence the outcome is comorbidities. Despite having $22 \%$ of the patients in this cohort with other comorbidities (Table 2), the overall surgical and bioabsorbable material-related complications were not higher than in other published series. The unanticipated return to the operating room due to a broken plate was evident on postoperative day 1 . The underlying cause of this plate fracture is unclear.

Our cohort has the advantages of a predefined age group, consistency in surgeons and implant product, a variety of sutures and syndromes involved, and extended follow-up. Our standard postoperative follow-up schedule includes visits at $1,3,6$, and 12 months and the average in this series was five postoperative visits. Over $80 \%$ of patients in this series have at least 12 months of follow-up, substantially decreasing the risk of a missed event. A limitation of this study is the retrospective, case series design; however, given 
Table 4 Literature review of resorbable fixation use in pediatric skull deformities

\begin{tabular}{|c|c|c|c|c|c|c|c|}
\hline $\begin{array}{l}\text { Primary } \\
\text { author }\end{array}$ & Year & Implant & $\begin{array}{l}\text { No. of } \\
\text { patients in } \\
\text { study }\end{array}$ & $\begin{array}{l}\text { Age } \\
\text { (mean, } \\
\text { range; } \\
\text { months) }\end{array}$ & $\begin{array}{l}\text { Diagnoses } \\
\text { included }\end{array}$ & $\begin{array}{l}\text { Mean } \\
\text { length of } \\
\text { follow-up } \\
\text { (months) }\end{array}$ & $\begin{array}{l}\text { Complications } \\
(n, \%)\end{array}$ \\
\hline Eppley & 1997 & LactoSorb $^{\mathrm{a}}$ & 100 & $9,6-12$ & Craniosynostosis & $15,6-24$ & 0,0 \\
\hline Goldstein & 1997 & LactoSorb & 8 & $38,6-120$ & $\begin{array}{l}\text { Craniosynostosis } \\
\text { and encephalocele }\end{array}$ & 4.5 & $1,12.5$ \\
\hline Kumar & 1997 & LactoSorb & 22 & $76,5-228$ & $\begin{array}{l}\text { Craniosynostosis } \\
\text { and congenital } \\
\text { craniofacial lesions }\end{array}$ & $0.5-4$ & $1,4.5$ \\
\hline Tharanon & 1998 & LactoSorb & 33 &,$- 4-144$ & $\begin{array}{l}\text { Craniosynostosis, } \\
\text { Hydrocephalus } \\
\text { and congenital } \\
\text { craniofacial lesions }\end{array}$ & 12 & $1,3.0$ \\
\hline Aria & 2000 & Fixsorb $^{b}$ & 3 &,$- 2-10$ & Craniosynostosis & $16-18$ & 0,0 \\
\hline Kurpad & 2000 & LactoSorb & 51 & $36,1-120$ & $\begin{array}{l}\text { Craniosynostosis and } \\
\text { encephalocele }\end{array}$ & 24 & $2,3.9$ \\
\hline Imola & 2001 & LactoSorb & 55 & $17,5-78$ & $\begin{array}{l}\text { Craniosynostosis, } \\
\text { craniofacial syndromes, } \\
\text { and acquired disorders }\end{array}$ & $6-36$ & $4,7.0$ \\
\hline Burstein & 2002 & LactoSorb & 21 & $53,0.2-180$ & $\begin{array}{l}\text { Craniofacial } \\
\text { syndromes }\end{array}$ & 24 & $2,9.5$ \\
\hline Cohen & 2002 & MacroPore $^{c}$ & 5 &,$- 3-8$ & Sagittal synostosis & $3-12$ & 0,0 \\
\hline Eppley & 2004 & LactoSorb & 1883 &,$-<24$ & $\begin{array}{l}\text { Frontal synostosis } \\
\text { and occipital } \\
\text { deformation }\end{array}$ & - & $25,1.3$ \\
\hline Burstein & 2006 & LactoSorb & 60 & $7,4-15$ & Craniosynostosis & 24 & 8,13 \\
\hline Greenburg & 2006 & RapidSorb $^{\mathrm{d}}$, Bone Cement ${ }^{\mathrm{a}, \mathrm{d}}$ & 50 & $6,0.25-24$ & Metopic synostosis & 144 & 1,2 \\
\hline Serlo & 2007 & PLGA $^{\mathrm{e}}$ & 10 & $14,7-35$ & Craniosynostosis & 42 & 1,10 \\
\hline Sanger & 2007 & Craniosorb $^{\mathrm{f}}$, Bioasorb PDX ${ }^{\mathrm{g}}$, LactoSorb & 52 & $8,2-49$ & Craniosynostosis & 17 & $3,5.8$ \\
\hline Ahmad & 2008 & LactoSorb & 146 & $15,2-192$ & Craniosynostosis & 12 & $5,3.4$ \\
\hline Aldana & 2008 & Sonic Welding ${ }^{\mathrm{h}}$ & 28 & $66,2-216$ & $\begin{array}{l}\text { Craniosynostosis, } \\
\text { tumor, and traumatic } \\
\text { injury }\end{array}$ & 11.5 & $1,3.6$ \\
\hline Arnaud & 2009 & Sonic Welding ${ }^{\mathrm{h}}$ & 20 & $16,3-30$ & $\begin{array}{l}\text { Craniosynostosis } \\
\text { and congenital } \\
\text { craniofacial defect }\end{array}$ & $>30$ & 1,5 \\
\hline Munoz-Casado & 2009 & LactoSorb & 216 & $6,4-24$ & Craniosynostosis & $6-60$ & $7,3.2$ \\
\hline Guzman & 2011 & RabidSorb & 70 & $6.5,1-27$ & Craniosynostosis & 15 & $2,2.9$ \\
\hline
\end{tabular}

- unavailable

${ }^{a}$ Lorenz Surgical, BioMet, Jacksonville, FL

${ }^{\mathrm{b}}$ Fixsorb-MX; Takiron Co., Ltd., Osaka, Japan

${ }^{\mathrm{c}}$ MacroPore, Inc., San Diego, CA

${ }^{\mathrm{d}}$ Synthes Inc, Paoli, PA

${ }^{\mathrm{e}}$ Biosorb PDX or Inion CPS baby, Tampere, Finland

${ }^{\mathrm{f}}$ Codman-Johnson \& Johnson, Raynham, MA

${ }^{\mathrm{g}}$ Bionx Implants Inc, Blue Bell, PA

${ }^{\mathrm{h}}$ SonicWeld Rx, KLS Martin L.P.

the low number of patients and good outcome with resorbable plates, a randomized, prospective clinical trial is impractical. Overall, in comparison to prior studies of resorbable plates, our cohort confirms bioavailable fixation systems to be safe and effective for the treatment of craniofacial deformities in children.

\section{Conclusion}

The bioabsorbable fixation system for cranial vault reconstruction in children less than 2 years of age is safe with very low morbidity rates. In our cohort, the risk of inflammation related to bioabsorbable fixation system was $1 \%$. It is 
important to disclose to families the risks and benefits of using these systems, as summarized in our review.

Acknowledgments This research was supported in part by an indirect educational grant from Synthes to Stanford University School of Medicine. Additional funding was from the Division of Pediatric Neurosurgery at Stanford University and Lucile Packard Children's Hospital.

Conflict of interest Dr. H. Peter Lorenz is a consultant for Synthes Corporation. His work with Synthes does not involve any of the Synthes' materials or devices described in the article. All other authors have no personal, financial or institutional interest in any of the drugs, materials, or devices described in this article.

\section{References}

1. Ahmad N, Lyles J, Panchal J, Deschamps-Braly J (2008) Outcomes and complications based on experience with resorbable plates in pediatric craniosynostosis patients. J Craniofac Surg 19 (3):855-860. doi:10.1097/SCS.0b013e31816ae358

2. Al-Sukhun J, Tornwall J, Lindqvist C, Kontio R (2006) Bioresorbable poly-L/DL-lactide (P[L/DL]LA 70/30) plates are reliable for repairing large inferior orbital wall bony defects: a pilot study. J Oral Maxillofac Surg 64(1):47-55. doi:10.1016/j.joms.2005.09.013

3. Arnaud E, Renier D (2009) Pediatric craniofacial osteosynthesis and distraction using an ultrasonic-assisted pinned resorbable system: a prospective report with a minimum 30 months' follow-up. J Craniofac Surg 20(6):2081-2086. doi:10.1097/SCS.0b013e3181be8854

4. Ascherman JA, Foo R, Nanda D, Parisien M (2008) Reconstruction of cranial bone defects using a quick-setting hydroxyapatite cement and absorbable plates. J Craniofac Surg 19(4):1131-1135. doi:10.1097/SCS.0b013e31817bd83e

5. Ayhan S, Tugay C, Ortak T, Prayson R, Parker M, Siemionow M, Papay FA (2002) Effect of bioabsorbable osseous fixation materials on dura mater and brain tissue. Plast Reconstr Surg 109 (4):1333-1337
6. Bell RB, Kindsfater CS (2006) The use of biodegradable plates and screws to stabilize facial fractures. J Oral Maxillofac Surg 64 (1):31-39. doi:10.1016/j.joms.2005.09.010

7. Eppley BL (1997) Potential for guided bone regeneration and bone graft fixation with resorbable membranes in pediatric craniofacial surgery. J Craniofac Surg 8(2):127-128

8. Eppley BL, Morales L, Wood R, Pensler J, Goldstein J, Havlik RJ, Habal M, Losken A, Williams JK, Burstein F, Rozzelle AA, Sadove AM (2004) Resorbable PLLA-PGA plate and screw fixation in pediatric craniofacial surgery: clinical experience in 1883 patients. Plast Reconstr Surg 114(4):850-856, discussion 857

9. Guzman R, Looby JF, Schendel SA, Edwards MS (2011) Frontoorbital advancement using an en bloc frontal bone craniectomy. Neurosurgery 68(1 Suppl Operative):68-74. doi:10.1227/ NEU.0b013e31820780cd

10. Imola MJ, Hamlar DD, Shao W, Chowdhury K, Tatum S (2001) Resorbable plate fixation in pediatric craniofacial surgery: longterm outcome. Arch Facial Plast Surg 3(2):79-90

11. Jackson IT, Baghaki S (2009) Reconstruction of cranial bone defects using a quick-setting hydroxyapatite cement and absorbable plates. J Craniofac Surg 20(2):580-581. doi:10.1097/ SCS.0b013e31819ba5fl

12. Kurpad SN, Goldstein JA, Cohen AR (2000) Bioresorbable fixation for congenital pediatric craniofacial surgery: a 2-year followup. Pediatr Neurosurg 33(6):306-310

13. Losken HW, van Aalst JA, Mooney MP, Godfrey VL, Burt T, Teotia S, Dean SB, Moss JR, Rahbar R (2008) Biodegradation of Inion fast-absorbing biodegradable plates and screws. J Craniofac Surg 19(3):748-756. doi:10.1097/SCS.0b013e31816aab24

14. Mackool R, Yim J, McCarthy JG (2006) Delayed degradation in a resorbable plating system. J Craniofac Surg 17(1):194-197. doi:10.1097/01.scs.0000194167.50546.7e, discussion 197-198

15. Munoz-Casado MJ, Romance AI, Garcia-Recuero JI (2009) Bioabsorbable osteofixation devices in craniosynostosis. Clinical experience in 216 cases. Neurocirugia (Astur) 20(3):255-261

16. Pang D, Tse HH, Zwienenberg-Lee M, Smith M, Zovickian J (2005) The combined use of hydroxyapatite and bioresorbable plates to repair cranial defects in children. J Neurosurg 102(1 Suppl):36-43. doi:10.3171/ped.2005.102.1.0036

17. Tharanon W, Sinn DP, Hobar PC, Sklar FH, Salomon J (1998) Surgical outcomes using bioabsorbable plating systems in pediatric craniofacial surgery. J Craniofac Surg 9(5):441-444, discussion $445-447$ 